\title{
Structural Evaluation of Masonry Sewer Pipes Under Transverse Settlement Due to Tunneling
}

\author{
Parsa Heydarpour
}

\begin{abstract}
The intention of this research is to perform structural evaluation on masonry sanitary sewer pipes impacted by tunnel excavation. Until about 1900, it was common to use several layers of brick to construct municipal sanitary sewer lines, and currently thousands of miles of brick sewer lines are still in service. The construction of new underground facilities inevitably disturbs the soil above and will have an impact on the existing masonry sanitary sewer pipes within the zone of influence of the excavation. Masonry pipes are typically susceptible to the longitudinal interaction failure mechanism at the hogging zone of the settlement trough due to their low tensile capacity. In this research standard eggshaped section for brick sewer were subjected to ground settlements obtained using Attewell method. The greenfield condition is assumed to be applicable with homogeneous ground conditions. The impact of the depth to the tunnel axis and trough width parameter on the settlement trough and associated strains developed in the pipes are subjected to investigation. Tensile strain developed due to axial strain and bending moment are calculated for five different section sizes. Mitigation measures and recommendations are provided
\end{abstract}

Index Terms-Masonry Sanatory Sewer, Longitudinal Interaction Failure Mechanism, Transverse Settlement Due to Tunneling, Empirical Ground Settlement.

\section{INTRODUCTION}

Until about 1900, Large sewers were generally constructed of brick. It was common to build the sewer structures as a combined brick masonry and concrete [1],[2]; the concrete was used for the foundation of brick sewer or for reinforcing or backing up brick arches such that inverts were built out of concrete and arches were built out of bricks [3]. Several layers of brick were used to construct municipal sanitary sewer lines. Currently, thousands of miles of brick sewer lines are still in service in cities such as Washington DC, London, Paris, etc [3].

Further development of cities results in the need for improved infrastructure systems. Subsurface structures such as tunnels are becoming more desirable for infrastructure projects as spaces on the ground are limited[4]. The construction of new underground facilities inevitably disturbs the soil above and will have an impact on the existing structures within the zone of influence of the excavation. The response of the existing structures is dependent to their geometry, construction type and overall structural condition [2], [5], [6]. It should be mentioned that typically there is little knowledge among property owners regarding the history of deformations experienced by the

Published on April 29, 2019.

P. Heydarpour was with The George Washington University, DC, 20057 USA. He is now with Subsurface and Tunnel Engineering LLC, Frederick, MD 21704 USA (e-mail: parsa.heydarpour @ gmail.com). structure.

The relationship between surface settlements and tunnel depth is neither simple nor linear [7]. Typically, ground movements depend on tunnel geometry and depth, excavation methods, workmanship quality, and geotechnical conditions. It is widely accepted that a transverse section of the Greenfield settlement trough can be obtained with acceptable precision by a reversed Gaussian curve.

\section{BACKGROUND AND LITERATURE REVIEW}

The structural behavior of a buried pipeline impacted by tunneling depends on the interaction of the displaced soil with the lining of the pipeline. Vorster proposes five soilstructure interaction mechanisms for pipeline failure[8]. These failure mechanisms are: (Mechanism 1): Global Greenfield soil settlement; (Mechanism 2): Gap formation below the pipe; (Mechanism 3): Positive downdrag failure the pipe settles more than the soil; (Mechanism 4): Negative downdrag failure - the soil settles more than the pipe; (Mechanism 5): Longitudinal interaction. Among the aforementioned failure mechanisms masonry pipes are the most susceptible to the longitudinal interaction due to their low tensile capacity.

Longitudinal interaction is referred to the forces transmitted to the pipe as a result of horizontal soil strains. [2] The worst location for pipes is typically within the hogging zones where horizontal strains applies additional tensile strain on the pipe which encourages tensile fracture or joint pullout [8], [3].

The volume loss $\left(\mathrm{V}_{\mathrm{L}}\right)$ is typically expressed as a percentage of the excavated ground volume. It is assumed that the area bounded by the undisturbed ground surface and settlement trough is equal to the ground volume loss caused by tunneling operations. The volume loss depends on the tunneling technique and excavation practices (such as the speed of the TBM, applied face pressure, and contact grouting timing and pressure).

For masonry structures TMS 602-13 (Building Code Requirements and Specification for Masonry Structures) specifies that the modulus of rupture is approximately 133 psi [9]. A strength factor $(\phi)$ for non-reinforced masonry is considered as 0.6 for flexural and axial load. This results to approximate allowable tensile stress value of 80 psi. According to ASCE 7-16 (Minimum Design Loads For Buildings and Other Structures), load factor for selfstraining loads including movement due to differential settlement shall not be less than 1.0[10]. Therefore, the stresses obtained from the analysis shall be compared to the allowable stress indicated above with consideration of utility age and condition. 


\section{METHOD}

This research intends to evaluate the standard egg-shaped masonry sewer underground settlement induced by tunnel excavation. The maximum tensile stress induced by axial strain or bending is compared to the allowable limit proposed by TMS 602-13.

\section{A. Evaluation of Ground Settlement}

The Attewell method was used to estimate ground surface settlement due to tunneling [11]. The Attewell method is based on an inverted Gaussian distribution method and. This method was initially developed by Peck and has been further investigated by many researchers including Cording, Attewell, and O'Reilly and New [12], [13],[11], and [14].

The Gaussian distribution method proposed by Peck is presented in Eq.1.

$S(x)=S_{\text {max }} \cdot e^{\left(\frac{-x^{2}}{2 i^{2}}\right)}$

$S_{\text {max }}=0.313 \frac{V_{L} D^{2}}{i}$

Where, $\mathrm{S}$ is the vertical surface settlement at a horizontal distance $\mathrm{x}$, and $S_{\max }$ is the maximum vertical surface settlement, $\mathrm{x}$ is the horizontal distance between tunnel center line and the point where settlement is being evaluated, and $\mathrm{i}$ is the horizontal distance between the tunnel centerline and point of inflexion along the settlement trough.

$i$ is a function of the depth and is broadly independent of the tunnel construction method. Eq. 2 presents the relationship between $i$ and $Z_{0}$ as suggested by Attewell (1982).

$i=K Z_{0}$

Where, $Z_{0}$ is the depth to the tunnel axis; and $\mathrm{K}$ is the trough width parameter which depends on soil type and behavior. Table I presents the trough width parameter $\mathrm{K}$ for different soil types.

\begin{tabular}{ll} 
TABLE I: TROUGH WIDTH PARAMETER K \\
\hline \hline Parameter K \\
\hline Stiff Clay & $0.4-0.5$ \\
Soft Silty Clay & $0.6-0.7$ \\
Sand above GW & $0.2-0.3$ \\
Sand below GW & $0.4-0.5$ \\
\hline \hline
\end{tabular}

Horizontal displacement $\mathrm{U}$ is related to the settlement $\mathrm{S}$ by the expression presented in Eq.3.

$$
U(x)=\frac{s(x) \cdot x}{z_{0}}
$$

The horizontal strain in the transverse direction is obtained by differentiating the horizontal displacement with respect to $\mathrm{y}$ and is presented in Eq.4.

$$
\varepsilon_{h}(x)=\frac{d S_{h}}{d x}=\left(-\frac{x^{2}}{i^{2}}+1\right) \frac{s(x)}{z_{0}}
$$

Figure 1 presents the schematics of the vertical settlement, horizontal displacement, and horizontal strain. In this figure point of inflexion is also identified which can be used to separate the tension and compression zones.
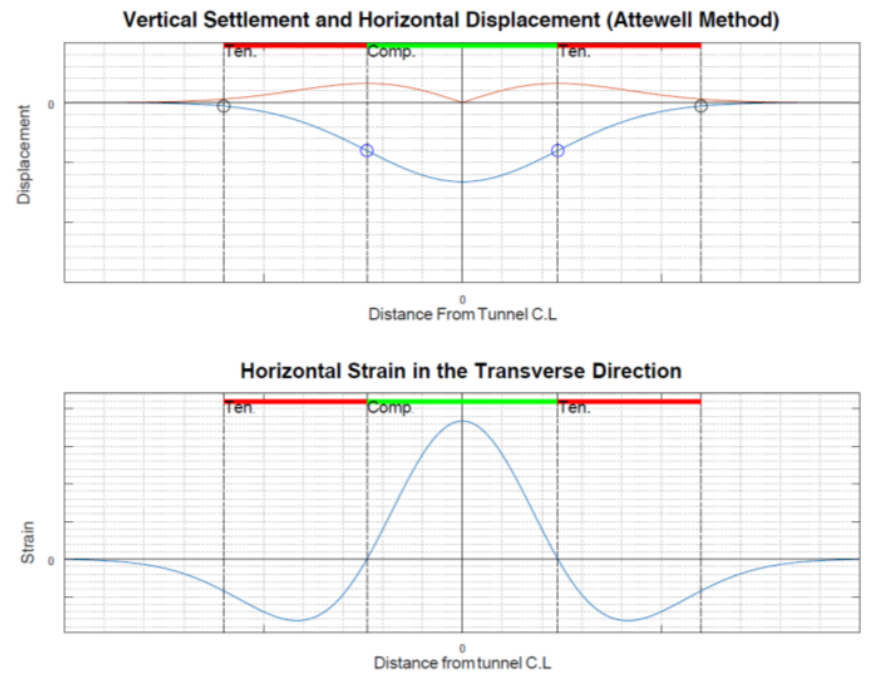

Fig. 1. Vertical Settlement, Horizontal Displacement, and Strain

Masonry pipes are typically susceptible to the longitudinal interaction failure mechanism at the hogging zone of the settlement trough due to their low tensile capacity.

\section{B. Volume Loss $\left(V_{L}\right)$}

The choice of the volume loss parameter $\mathrm{V}_{\mathrm{L}}$ is of considerable importance and the appropriate value is related to experience of the tunneling technique and ground conditions at the particular project for which predictions are required. In this respect, good case history data is vital.

In recent years TBM performance has improved considerably and has reduced volume losses. Earth Pressure Balance Machines (EPBM) has significantly reduced ground movements and volume loss. This research is not intended to study the impact of different volume losses.

\section{Parameters of the study}

The depth to the tunnel axis $\left(Z_{0}\right)$, trough width parameter $(\mathrm{K})$, will have the most significant impact on the settlement trough. Volume loss and tunnel diameter are assumed as constants. The variables for this study and the steps for variation are presented in Table 2.

\begin{tabular}{lll}
\multicolumn{3}{c}{ TABLE II: PARAMETERS OF THE STUDY } \\
\hline \hline Parameter K & Range & Step \\
\hline Depth to the tunnel axis $\left(Z_{0}\right)$ & $55 \mathrm{ft} .-125 \mathrm{ft}$. & $10 \mathrm{ft}$. \\
Trough width parameter $(\mathrm{K})$ & $0.3-0.8$ & 0.1 \\
Volume loss $\left(\mathrm{V}_{\mathrm{L}}\right)$ & $0.5 \%$ & N/A \\
Tunnel Diameter & $25 \mathrm{ft}$. & N/A \\
\hline \hline
\end{tabular}

The cover over diameter ratio (C/D) is varying between 1.7 to 4.5 in this study.

\section{Limitation of Analysis}

Attewell method provides results with good agreement with ground recorded data under following conditions: (1) Greenfield conditions should be applicable as the presence of structures might disturb the displacement field induced by tunneling. (2) Single tunnel or multiple tunnels without interactions. (3) Homogeneous ground conditions. (4) Short term conditions as this empirical method does not incorporate soil displacements due to consolidation. 


\section{E. Standard Egg-Shaped Section}

Five different section sizes have been subjected to analysis which their geometric properties are presented in Table III. The cradle for these structures is assumed to be constructed using a low strength concrete with modulus of elasticity of $1800 \mathrm{ksi}$. The modulus of elasticity of the vitrified brick is assumed to be $700 \mathrm{ksi}$. Concrete is chosen as the base material and the brick work is converted into equivalent concrete section.

TABLE III: GEOMETRIC PROPERTIES OF THE INVESTIGATED SEWERS

\begin{tabular}{ccccccc}
\hline \hline Section ID & $\begin{array}{c}\text { Area } \\
\text { (total) } \\
\text { in }^{2}\end{array}$ & $\begin{array}{c}\text { Equivalent } \\
\text { Area } \\
(\text { Brick }) \\
\text { in }^{2}\end{array}$ & $\begin{array}{c}\text { Area } \\
(\text { Cradle }) \\
\text { in }^{2}\end{array}$ & $\begin{array}{c}\mathrm{I}_{\mathrm{xx}} \\
\text { in }^{4}\end{array}$ & $\begin{array}{c}\mathrm{Y}_{\text {Bar }} \\
\text { in }\end{array}$ & $\begin{array}{c}\mathrm{C}_{\text {brick }} \\
\text { in }\end{array}$ \\
\hline $3 \mathrm{ft}$ & 1714.3 & 266.4 & 1450.65 & 317000 & 18.9 & 39.1 \\
$3 \mathrm{ft}-9$ in & 2078.2 & 326.4 & 1759.91 & 513600 & 21.4 & 45.5 \\
$4 \mathrm{ft}-6$ in & 2459.9 & 382.0 & 2086.72 & 780800 & 23.9 & 52.1 \\
$5 \mathrm{ft}-9$ in & 3143.0 & 472.1 & 2678.17 & 1419000 & 27.8 & 63.1 \\
$6 \mathrm{ft}-6$ in & 3595.3 & 538.4 & 3075.86 & 1954000 & 30.2 & 69.7 \\
\hline \hline
\end{tabular}

Schematics of the standard egg-shaped sections are presented in Figure 2.

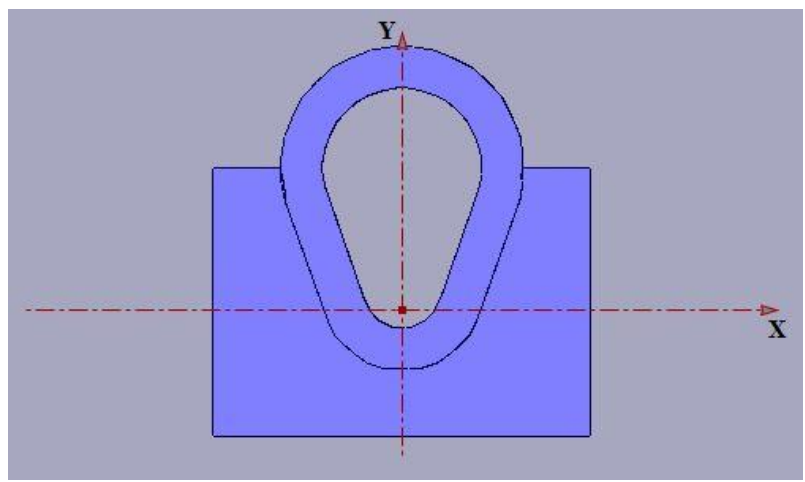

Fig. 2. Standard Egg-Shaped Section

\section{RESULTS}

Table IV present the results of the maximum vertical settlement and horizontal displacement assuming the volume loss of $0.5 \%$.

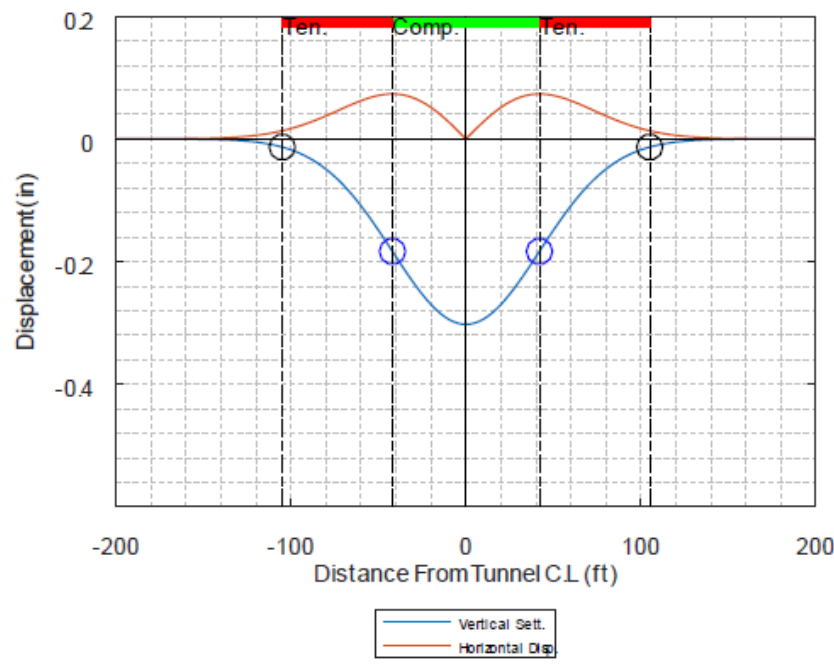

Fig. 3. Settlement Trough $\left(\mathrm{K}=0.4, Z_{0}=105 \mathrm{ft}\right.$., $\left.\mathrm{VL}=0.5 \%\right)$

\section{A. Vertical and Horizontal Displacements}

Table IV presents the maximum vertical settlement and horizontal displacements for the investigated cases introduced earlier.

TABLE IV: ATTEWELL METHOD RESULTS FOR VL $=0.5 \%$

\begin{tabular}{|c|c|c|c|c|c|c|c|c|c|}
\hline \multirow[b]{2}{*}{$\mathrm{K}$} & & \multicolumn{8}{|c|}{ 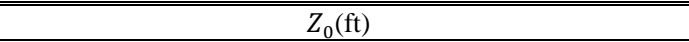 } \\
\hline & & $n$ & 6 & $\stackrel{n}{n}$ & $\mathscr{\infty}$ & そ & 으 & $\exists n$ & $\simeq$ in \\
\hline \multirow{2}{*}{0.3} & V(in.) & -0.71 & -0.60 & -0.52 & -0.46 & -0.41 & -0.37 & -0.34 & -0.31 \\
\hline & H(in.) & 0.13 & 0.11 & 0.09 & 0.08 & 0.07 & 0.07 & 0.06 & 0.06 \\
\hline \multirow{2}{*}{0.4} & V(in.) & -0.53 & -0.45 & -0.39 & -0.35 & -0.31 & -0.28 & -0.26 & -0.23 \\
\hline & H(in.) & 0.13 & 0.11 & 0.09 & 0.08 & 0.07 & 0.07 & 0.06 & 0.06 \\
\hline \multirow{2}{*}{0.5} & V(in.) & -0.43 & -0.36 & -0.31 & -0.28 & -0.25 & -0.22 & -0.20 & -0.19 \\
\hline & H(in.) & 0.13 & 0.11 & 0.09 & 0.08 & 0.07 & 0.07 & 0.06 & 0.06 \\
\hline \multirow{2}{*}{0.6} & V(in.) & -0.36 & -0.30 & -0.26 & -0.23 & -0.21 & -0.19 & -0.17 & -0.16 \\
\hline & H(in.) & 0.13 & 0.11 & 0.09 & 0.08 & 0.07 & 0.07 & 0.06 & 0.06 \\
\hline \multirow{2}{*}{0.7} & V(in.) & -0.30 & -0.26 & -0.22 & -0.20 & -0.18 & -0.16 & -0.15 & -0.13 \\
\hline & H(in.) & 0.13 & 0.11 & 0.09 & 0.08 & 0.07 & 0.07 & 0.06 & 0.06 \\
\hline \multirow[t]{2}{*}{0.8} & V(in.) & -0.27 & -0.23 & -0.20 & -0.17 & -0.15 & -0.14 & -0.13 & -0.12 \\
\hline & $\mathrm{H}$ (in.) & 0.13 & 0.11 & 0.09 & 0.08 & 0.07 & 0.07 & 0.06 & 0.06 \\
\hline
\end{tabular}

\section{B. Tensile Strain}

In this research it is assumed that the pipe lines are perpendicular to the tunnel alignment which can be considered as the worst case since the maximum tensile strain is being developed. Table $\mathrm{V}$ present the results of the maximum compressive and tensile strain for the case with volume loss of $0.5 \%$

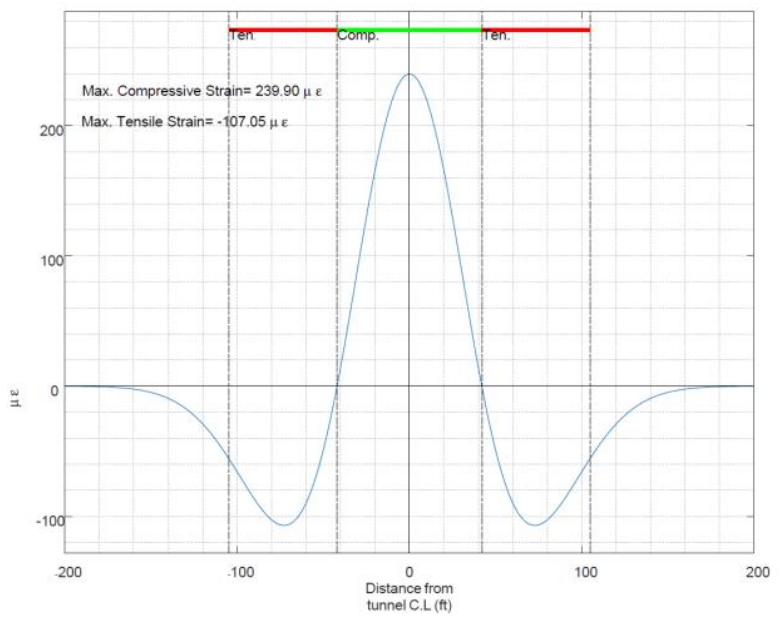

Fig. 4. Horizontal Strain $\left(\mathrm{K}=0.4, Z_{0}=105 \mathrm{ft}\right.$., $\left.\mathrm{VL}=0.5 \%\right)$

TABLE V: MAXIMUM COMPRESSIVE AND TENSILE STRAIN, $(\mu \varepsilon)$ $Z_{0}(\mathrm{ft})$

\begin{tabular}{|c|c|c|c|c|c|c|c|c|c|}
\hline K & & $n$ & 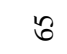 & 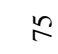 & $\mathscr{n}$ & $\curvearrowleft$ & $\stackrel{\varrho}{0}$ & $\stackrel{n}{=}$ & 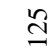 \\
\hline \multirow{2}{*}{0.3} & Com. $^{1}$ & -478 & -342 & -258 & -201 & -161 & -132 & -110 & -93 \\
\hline & Ten. $^{1}$ & 1078 & 772 & 580 & 451 & 361 & 296 & 247 & 209 \\
\hline \multirow{2}{*}{0.4} & Com. $^{1}$ & -360 & -258 & -194 & -151 & -121 & -99 & -83 & -70 \\
\hline & Ten. $^{1}$ & 808 & 579 & 435 & 338 & 271 & 222 & 185 & 157 \\
\hline \multirow{2}{*}{0.5} & Com. $^{1}$ & -289 & -206 & -155 & -121 & -97 & -79 & -66 & -56 \\
\hline & Ten. $^{1}$ & 647 & 463 & 348 & 271 & 217 & 177 & 148 & 125 \\
\hline \multirow{2}{*}{0.6} & Com. $^{1}$ & -240 & -172 & -129 & -101 & -81 & -66 & -55 & -47 \\
\hline & Ten. $^{1}$ & 539 & 386 & 290 & 226 & 181 & 148 & 123 & 104 \\
\hline \multirow{2}{*}{0.7} & Com. $^{1}$ & -206 & -147 & -111 & -86 & -69 & -57 & -47 & -40 \\
\hline & Ten. $^{1}$ & 462 & 331 & 248 & 193 & 155 & 127 & 106 & 89 \\
\hline \multirow{2}{*}{0.8} & Com. $^{1}$ & -180 & -129 & -97 & -76 & -60 & -49 & -41 & -35 \\
\hline & Ten. $^{1}$ & 404 & 289 & 217 & 169 & 135 & 111 & 92 & 78 \\
\hline
\end{tabular}

${ }^{1}$ All the strains are presented are in micro strain. 


\section{Axial Stresses}

The axial stress induced in the masonry pipes due to longitudinal strain are independent of the section sizes and is presented in the Table VI. Cases which the axial tension is above 80 psi tensile capacity of the masonry pipes are highlighted by red font. In these cases, even without consideration of the tension induced due to bending the masonry pipes will experience tensions above threshold proposed by TMS 602-13 (Building Code Requirements and Specification for Masonry Structures).

TABLE VI: AXIAL TENSILE STRESSES (PSI)

\begin{tabular}{llllllllll}
\hline \hline & & & \multicolumn{8}{c}{$Z_{0}(\mathrm{ft})$} \\
$\mathrm{K}$ & & $\curvearrowleft$ & $\curvearrowleft$ & $\curvearrowleft$ & $\curvearrowleft$ & $\curvearrowleft$ & $\ddots$ & $\ddots$ & $\curvearrowleft$ \\
\hline 0.3 & Ten. & -334 & -240 & -181 & -141 & -113 & -92 & -77 & -65 \\
0.4 & Ten. & -252 & -181 & -136 & -106 & -85 & -69 & -58 & -49 \\
0.5 & Ten. & -202 & -144 & -109 & -84 & -68 & -55 & -46 & -39 \\
0.6 & Ten. & -168 & -121 & -91 & -70 & -56 & -46 & -39 & -33 \\
0.7 & Ten. & -144 & -103 & -78 & -60 & -48 & -40 & -33 & -28 \\
0.8 & Ten. & -126 & -90 & -68 & -53 & -42 & -35 & -29 & -24 \\
\hline \hline
\end{tabular}

All the stresses are in psi.

\section{A. Bending Stresses}

Bending stresses for the five different section sizes introduced in the Table III are calculated. The maximum tension is occurring in the hogging zone of the settlement curve and will induce tension in the brick which is located on the upper side of the section. The bending stress induced in the masonry pipes are presented in the Table VII. Cases which the tension is above 80 psi tensile capacity of the masonry pipes are highlighted by red font.

TABLE VII: BENDING STRESSES (PSI)

\begin{tabular}{|c|c|c|c|c|c|c|c|c|c|}
\hline \multirow[b]{2}{*}{$\mathrm{K}$} & & \multicolumn{8}{|c|}{ 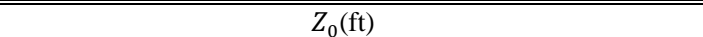 } \\
\hline & & $n$ & 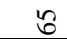 & $n$ & $\infty$ & 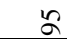 & 으 $n$ & $\exists n$ & $I n$ \\
\hline \multicolumn{10}{|c|}{$3 \mathrm{ft}$ Section } \\
\hline 0.3 & Ten. & -381 & -231 & -150 & -103 & -74 & -55 & -42 & -32 \\
\hline 0.4 & Ten. & -161 & -97 & -63 & -44 & -31 & -23 & -18 & -14 \\
\hline 0.5 & Ten. & -82 & -50 & -32 & -22 & -16 & -12 & -9 & -7 \\
\hline 0.6 & Ten. & -48 & -29 & -19 & -13 & -9 & -7 & -5 & -4 \\
\hline 0.7 & Ten. & -30 & -18 & -12 & -8 & -6 & -4 & -3 & -3 \\
\hline 0.8 & Ten. & -20 & -12 & -8 & -5 & -4 & -3 & -2 & -2 \\
\hline \multicolumn{10}{|c|}{$3 \mathrm{ft}-9$ in Section } \\
\hline 0.3 & Ten. & -444 & -269 & -175 & -120 & -86 & -64 & -49 & -38 \\
\hline 0.4 & Ten. & -187 & -113 & -74 & -51 & -36 & -27 & -20 & -16 \\
\hline 0.5 & Ten. & -96 & -58 & -38 & -26 & -19 & -14 & -10 & -8 \\
\hline 0.6 & Ten. & -55 & -34 & -22 & -15 & -11 & -8 & -6 & -5 \\
\hline 0.7 & Ten. & -35 & -21 & -14 & -9 & -7 & -5 & -4 & -3 \\
\hline 0.8 & Ten. & -23 & -14 & -9 & -6 & -5 & -3 & -3 & -2 \\
\hline \multicolumn{10}{|c|}{$4 \mathrm{ft}-6$ in Section } \\
\hline 0.3 & Ten. & -508 & -308 & -200 & -138 & -99 & -73 & -56 & -43 \\
\hline 0.4 & Ten. & -214 & -130 & -85 & -58 & -42 & -31 & -23 & -18 \\
\hline 0.5 & Ten. & -110 & -67 & -43 & -30 & -21 & -16 & -12 & -9 \\
\hline 0.6 & Ten. & -64 & -38 & -25 & -17 & -12 & -9 & -7 & -5 \\
\hline 0.7 & Ten. & -40 & -24 & -16 & -11 & -8 & -6 & -4 & -3 \\
\hline 0.8 & Ten. & -27 & -16 & -11 & -7 & -5 & -4 & -3 & -2 \\
\hline \multicolumn{10}{|c|}{$5 \mathrm{ft}-9$ in Section } \\
\hline 0.3 & Ten. & -616 & -373 & -243 & -167 & -119 & -88 & -67 & -52 \\
\hline 0.4 & Ten. & -260 & -157 & -102 & -70 & -50 & -37 & -28 & -22 \\
\hline 0.5 & Ten. & -133 & -81 & -52 & -36 & -26 & -19 & -15 & -11 \\
\hline 0.6 & Ten. & -77 & -47 & -30 & -21 & -15 & -11 & -8 & -7 \\
\hline 0.7 & Ten. & -48 & -29 & -19 & -13 & -9 & -7 & -5 & -4 \\
\hline 0.8 & Ten. & -32 & -20 & -13 & -9 & -6 & -5 & -4 & -3 \\
\hline \multicolumn{10}{|c|}{$6 \mathrm{ft}-6$ in Section } \\
\hline 0.3 & Ten. & -680 & -412 & -268 & -184 & -132 & -98 & -74 & -58 \\
\hline 0.4 & Ten. & -287 & -174 & -113 & -78 & -56 & -41 & -31 & -24 \\
\hline 0.5 & Ten. & -147 & -89 & -58 & -40 & -28 & -21 & -16 & -13 \\
\hline 0.6 & Ten. & -85 & -51 & -34 & -23 & -16 & -12 & -9 & -7 \\
\hline 0.7 & Ten. & -54 & -32 & -21 & -14 & -10 & -8 & -6 & -5 \\
\hline 0.8 & Ten. & -36 & -22 & -14 & -10 & -7 & -5 & -4 & -3 \\
\hline
\end{tabular}

All the stresses are in psi.

\section{CONCLUSION}

Due to very low tensile capacity of the masonry sewer it is extremely difficult to maintain stresses within the allowable limits. There are only few cases with high $\mathrm{Z}_{0}$ value where the combined axial and bending stresses are within 80 psi limit. Increasing the tunnel depth significantly reduced the strains and stresses developed in the masonry sewers. Cases were trough width parameter $(\mathrm{K})$ has higher values the settlement trough is wider, and the maximum settlements are lower, as a result of that, lower maximum stresses and strains are observed. Stresses obtained for all cases with low depth to the tunnel axis $\left(Z_{0}\right)$ are above TMS 602-13 limit of 80 psi.

The construction of new underground facilities inevitably disturbs the soil above and will have an impact on the existing structures within the zone of influence of the excavation. Adjusting the face pressure of TBM to reduce the volume loss shall be considered to reduce displacements.

In cases where mitigation measures cannot be postponed, relining sections were will be exposes to maximum tensile stresses should be considered. In extreme cases permeation grouting shall be used as ground improvement mitigation measure.

This study used a constant volume loss of $0.5 \%$. For future work the impact of volume loss can be investigated on the settlement trough and induced stresses.

\section{REFERENCES}

[1] Y. Wang, Q. Wang, and K. Y. Zhang, "An analytical model for pipesoil-tunneling interaction," Procedia Eng., vol. 14, pp. 3127-3135, 2011.

[2] A. Klar, A. M. Marshall, K. Soga, and R. J. Mair, "Tunneling effects on jointed pipelines," Can. Geotech. J., vol. 45, no. 1, pp. 131-139, 2008.

[3] L. Metcalf and H. Prescott Eddy, American Sewerage Practice: Construction of sewers, 1 st ed.

[4] J. N. Franzius, "Behaviour of buildings due to tunnel induced subsidence A," Imperial College of Science, Technology and Medicine, 2003

[5] A. M. Marshall, "Tunnelling in sand and its effect on pipelines and piles," Univ. Cambridge, no. March, 2009.

[6] P. F. Silva, P. Heydarpour, and R. Burgueño, "Stability Index Evaluation of Slender RC Bridge Columns under Seismic and Gravity Loads," J. Bridg. Eng., vol. 24, no. 5, p. 04019029, 2019.

[7] E. Leca, B. New, and G. Reporter, "Settlements induced by tunneling in Soft Ground," Tunn. Undergr. Sp. Technol., vol. 22, no. 2, pp. 119$149,2007$.

[8] T. E. . Vorster, "The Effects of Tunneling on Buried Pipes," 2005.

[9] M. S. J. Committee, Building Code Requirements and Specification for Masonry Structures. 2013 Building Code Requirements and Specification for Masonry Structures - MSJC, 2013.

[10] ASCE/SEI 7 Minimum Design Loads For Buildings and Other Structures. Structural Engineering Institute, 2016.

[11] P. B. Attewell and J. P. Woodman, "Predicting the dynamic of ground settlement and its derivatives caused by tunnelling in soil," Gr. Eng., vol. 15 , no. 7 , pp. 13-22, 1982.

[12] R. B. Peck, "Deep Excavations and Tunnelling in Soft Ground," in 7th International Conference on Soil Mechanics and Foundation Engineering, 1969, pp. 266-290.

[13] E. J. Cording and W. . Hansmire, "Displacement around soft ground tunnels," in 5th Pan American Conf. on Soil Mech. \& Foundation Eng., 1975, pp. 571-633.

[14] M. P. O'Reilly and B. M. New, "Settlements above Tunnels in the United Kingdom - Their Magnitude and Prediction," Tunnelling, pp. 173-181, 1982. 


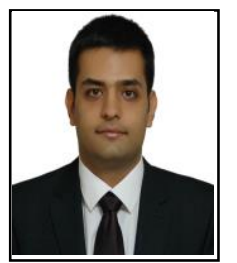

Parsa Heydarpour received his Bachelor of Science in Civil and Environmental Engineering from Department of Civil and Environmental Engineering in 2013 from University of Tehran, Iran. He continued his studies in structural engineering and received his Master of Science in 2015 form The George Washington University, Washington, DC, USA. He has persued his Ph.D. in structural Engineering at The Earthquake Engineering and Structures Laboratory at The George Washington University and received his Ph.D. in 2018. 